\title{
Eräästä ugrilaisten kielten postpositioperäisestä kaasussuffiksien perheestä
}

Kirjoitus pohjautuu Suomalais-Ugrilaisen Seuran 2. joulukuuta 2003 järjestämässä Matti Liimolan 100-vuotisjuhlaseminaarissa pidettyyn esitelmään.

\section{Johdannoksi}

Tieteemme historiassa Matti Liimola oli se, joka epäilemättä tunsi parhaiten vogulin kielen ja sen murteet sekä deskriptiivisesti että historiallisesti. Hän julkaisi suuren joukon tutkielmia vogulin eri kysymyksistä, ja valtaosa hänen tuloksistaan on osoittautunut oikeaksi. Liimolan julkaisuista olen käyttänyt ehkä eniten hänen monografiaansa vogulin nominien morfologiasta (Liimola 1963). Tässä teoksessa hän käsittelee mm. vogulin murteiden erään laajan postpositioperheen alkuperää, syntyä ja sen vastineita lähimmissä sukukielissä, ostjakissa ja unkarissa. Sen sisältämä selitys on yksi niistä harvoista Liimolan tarjoamista, jotka yritettiin hylätä. Nähdäkseni kuitenkin Liimola oli se tutkija, joka on löytänyt oikean ratkaisun, ja tästä johtuen haluaisin esittää, miksi hänen näkemyksensä on oikea ja miksi sitä vastustava näkökanta on erheellinen.

\section{2. n:n sisältävät postpositioperäiset ugrilaiset kaasussuffiksit}

Kyseessä on seuraava vogulin murteiden lokaalisuutta ilmaiseva suffiksiperhe (seuraavassa siteeraan Kanniston vogulin tietoja enimmäkseen fonemaattisessa transkriptiossa, mutta kun säilytän alkuperäisen kirjoitustavan, tiedon edessä on $\dagger$ ):

- latiivisuffiksi: TJ TČ -nā/-nä, -(ə)n, KU KM KO P LU -(ə)n, -nə, LO So -na, -(a)n,

- ablatiivisuffiksi: TJ -nāl/-näl, TČ -näl (Kanniston alkuperäisen transkription mukaisessa muodossa: $\left.-n \varepsilon l,-n \varepsilon^{`} l,-n \grave{\varepsilon} l\right), \mathrm{KU}$ KM KO LO So (hyvin harvoin myös) P -nal,

- komitatiivisuffiksi: TJ -nāt/-näat, TČ -nä̈t (Kanniston alkuperäisen transkription mukaisessa muodossa: -nct, -nغ̀t).

Näiden etymologiset vastineet muissa ugrilaisissa kielissä: ostj. latiivisuffiksi $O$ -na, komitatiivisuffiksi $\mathrm{VVj}$ Sur -nat/-nät, funktioltaan komitatiivinen postpositio Šer natay-; unk. datiivisuffiksi -nak/-nek, murteiden latiivisuffiksi -ni, -nyi, murteiden lokatiivisuffiksi -nott/-nött, -nitt, murteiden ablatiivisuffiksi 
-nól/-nöl, -núl/-nül (ks. Liimola 1963: 60-67, 78-98, 95, 120-123). Liimola on tietysti kerrannut hyvin perusteellisesti, minkälaisia näkemyksiä näiden elementtien historiallisesta taustasta ja niiden kehityksen vaiheista tutkimuskirjallisuudessa oli esitetty. Hyväksyen Budenzin (1884-1894: 385-386) ja Fokosin (esim. 1910) olettamukset hänkin lähti postpositiosta, joka palautuu substantiiviin *nä- 'Nähe, Seite od. dgl.', ja mainitsi samalla, että näillä ugrilaisten kielten elementeillä on vastineita samojedikielissä asti (Liimola 1963: 65, 95, 123).

\section{I. Liimolan esittämä $n: n$ sisältävien kaasussuffiksien etymologia}

Liimolan selityksen ytimen voi kiteyttää seuraavasti. Osassa Tavdan murteen alamurteita (Munkácsi TO, Kannisto TČ) mainituilla ablatiivin ja komitatiivin suffikseilla on vain etuvokaalinen edustaja, joka Liimolan mielestä on todistus siitä, että suffiksiperheen jäsenet ovat syntyneet itsenäisestä etuvokaalisesta sanasta, nimittäin postpositiosta (Liimola 1963: 66-67, 123; vrt. myös Riese 1992: 385). Tässä yhteydessä hän viittaa siihenkin, että tilanne on sama myös karitiivisuffiksin tapauksessa, esim. TJ † šattà $\bullet \sim$ TČ $\dagger$ šåtte $\bullet$ 'glücklos', vrt. TJ šat, TČ † šăt 'Glück' (Liimola 1963: 67), ja huomauttaa, että suffiksin vokalismin, toisin sanoen takavokaalisen vaihtoehdon puutteen tausta on epäselvä. Minulla ei ole tiedossa, että tämä suffiksi voisi palautua postpositioon. Mainitsen, että T. Itkonen on esittänyt ajatuksen tämän erikoispiirteen selvittämiseksi niin, että tämä suffiksi olisi joskus degrammatikalisoitunut ja sitten uudelleen agglutinoitunut ja grammatikalisoitunut:

Vokaalia ei Liimola ... tosin katso tyydyttävästi selitetyn. Koska sen edustus näyttää olevan kauttaaltaan sama kuin sm.-ugr. *ä:tä ensi tavussa edustavan kvog. * $* \bar{a}$ :n (vain TJ-murteessa mukautuminen vokaalisointuun), vaikuttaa siltä, että pääte on jossain vogulin vaiheessa hahmotettu postpositioksi ja tällöin yleistetty sen etuvokaalinen toisinto. (T. Itkonen 1992: 222.)

Itkosen mukaan samantyyppisen kehityksen alku on havaittavissa pohjoislapissa:

Rinnakkaistapauksen tällaiselle päätteen uudestaantulkinnalle tarjoaa pohjoislappi, jossa abessiivin pääte -tâgâ samoin häilyy taivutuspäätteen ja postposition rajoilla ja voi esiintyä itsenäisenä adverbinakin merkityksessä 'ilman' (T. Itkonen 1992: 222; vrt. Nevis 1988: 45.)

Tämä oletus on tietysti mahdollinen, mutta jää vain tyhjäksi hypoteesiksi. Nähdäkseni ajatus on epätodennäköinen senkin takia, että samasta *nä- 'Nähe, Seite' postpositiosta lähtöisin olevalla paikallissijasuffiksien perheen latiivisella morfeemilla on myös takavokaalinen muunnos alamurteessa TČ $-n \bar{a} \sim-n \bar{a}$. On mainittava vielä, että eivät tämän runsaslukuisen ugrilaisen suffiksiperheen Tavdan murteen jäsenetkään voineet liittyä kaasussuffikseina nomineihin vasta Tavdan murteen erkaannuttua muinaisvogulista. Kyseessä on pikemminkin 
alamurteessa TČ $(\approx$ TO) äänteenmuutos, joka on toteutunut vain umpitavuisissa suffikseissa ja jonka syy on epäselvä. Sääntöjen vastainen ilmiö on myös se, että ablatiivisuffiksin vokaali on tavallisesti lyhyempi (lyhyt) - joten se esiintyy hyvin harvoin murretta TJ vastaavalla tavalla - tai harvinaisemmin neljännespitkä (puolipitkä), ja että sen realisaatio on tässä alamurteessa hieman suppeampi, vrt. TČ $\dagger \ddot{u} t^{\prime}-n \varepsilon \bullet l$ 'aus dem Wasser' $\sim \mathrm{TJ} \dagger \varepsilon p \ddot{a} \bullet-n \ddot{a} l$ 'aus der Wiege', TČ $\dagger$ $i \bar{e}-n \hat{\varepsilon} \bullet l \sim T J \dagger i \bar{e}-n a ̀ \bullet l$ 'aus dem Fluß' (Liimola 1963: 60, 61). Sen sijaan komitatiivisuffiksin vokaalin pituus vastaa TJ:n suffiksin pituutta; vain harvoin tava-

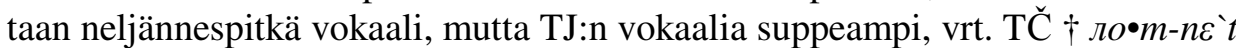

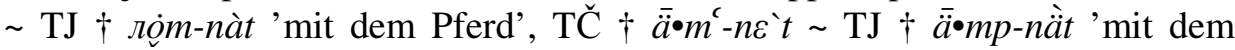
Hund'.

Tämänkaltainen epäsäännönmukaisuus on olemassa Tavdan murteen verbienkin morfologiassa. Sillä verbintaivutuksen muodolla, jolle olen antanut nimeksi konditionaali, on tunnus $\{\ddot{a} s k \ddot{a}\}$, mutta TČ:n alamurteessa tämäkin esiintyy vain etuvokaalisena; TJ:ssä etuvokaalinen variantti voi liittyä myös takavokaalisiin vartaloihin, takavokaalinen modussuffiksi sen sijaan vain taka-

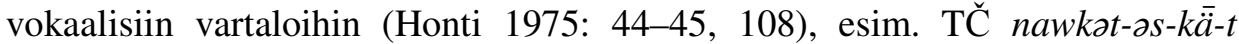
'wenn (jemand) anfängt', vrt. nawkat-as 'es begann' $\sim$ TJ $t \bar{o}-s-t \bar{a}-k \bar{\varepsilon}-t:$ jüw-t. ${ }^{1}$

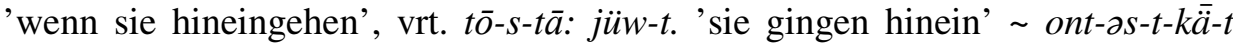
'wenn sie sich setzen', vrt. ont-əs-t 'sie setzten sich' (mp.).

Esittämistäni seikoista johtuu, että Tavdan murteessa vallitsevan vokaalisoinnun puutteellisuuden ja häilymisen takia emme voi tehdä johtopäätöksiä käsiteltyjen suffiksien edeltäjistä. Sen sijaan ostj. Šer nat-ay- on funktioltaan komitatiivinen postpositio, jonka ensimmäisen tavun vokaali voi palautua vain *ä:hän, sekä unk. datiivisuffiksi -nak/-nek, joka on käytössä eräänlaisena postpositiona persoonapronominien taivutuksessa, esim. nekem 'minulle', neked 'sinulle', neki 'hänelle' jne., viittaavat yksiselitteisesti alkuperäiseen etuvokaaliseen muotoon.

\section{Muiden tutkijoiden käsitykset n:n sisältävien kaasussuffiksien alkuperästä}

Muutamat kollegat eivät ole hyväksyneet Liimolan selitystä ja ovat esittäneet uusia etymologisia hypoteeseja näiden ugrilaisten kaasussuffiksien ja postpositioiden historiallisesta taustasta. Károly Rédei on esittänyt näiden elementtien lähtökohdaksi $*_{n}$-alkuista demonstratiivipronominia, eikä ole edes tullut maininneeksi Liimolan selitystä (Rédei 1973: 312-313; ks. alempana). Tibor Mikola on tutkinut hyvin perinpohjaisesti samojedikielten postpositioita ja tullut johtopäätökseen, että jurakin ńna-vartaloiset postpositiot (Mikola 1975: 24-45) ja

\footnotetext{
${ }^{1}$ Nykyään kirjoitan $\mathrm{T} \overline{\bar{\varepsilon}}: \mathrm{n} \bar{a}: \mathrm{n}$ sijasta.
} 
niiden vastineet muissa samojedikielissä (Mikola 1975: 164-170) voi yhdistää etymologisesti yllä esitettyihin ugrilaisten kielten suffikseihin. Näiden kaikkien alkuperäisestä lähteestä hän on kirjoittanut seuraavasti:

Für das Nordsamojedische, Wogulische und Ostjakische kann der Stamm *nä angenommen werden, doch wir können auch mit der Form *ne... rechnen. ... Abgesehen von wenigen Ausnahmen kann... die ausgedehnte Postpositionsfamilie auf die Grundform *nä-, *näk-, *näy- zurückgeführt werden. Ich halte es für wahrscheinlich, daß auch die schwieriger zu erklärenden Formen im Endergebnis ebenfalls auf die obigen zwei Lautformen zurückgehen. Dies ist um so glaubwürdiger, als die Grundbedeutung der gleichgestellten Suffixe offensichtlich 'Nähe' war und die auf die Nähe hinweisenden Pronomina im allgemeinen palatale Vokale enthalten. (Mikola 1975: 169.)

Jurakin ń $\bar{a}$ 'Freund, Gefährte' -sanan yhteydessä hän esittää:

... daß es ein Wort mit der Bedeutung 'Nähe' gab und sich daraus einerseits die Postpositionsfamilie $n^{\prime} \bar{a}$, andererseits das Substantiv ńa 'Freund' entwickelte. (Mikola 1975: 169-170.)

Janhunen on erottanut nämä kaksi ryhmää toisistaan: *nä- (postp.) (Janhunen 1977: 99) $\leftrightarrow *$ *äa 'Kamerad, Bruder, Schwester' (Janhunen 1977: 106). Mikolan näkökanta eroaa siis Liimolan selityksestä vain siinä, että hänkin lähtee pronominivartalosta. Myöhemmin Timothy Riese on hyväksynyt saman mielipiteen:

Der "Schönheitsfehler" an dieser Erklärung [kyseessä on selitys oletetusta substantiivista *nä- 'Nähe'; L. H.] liegt darin, daß sich das Element *nä 'Nähe, Seite' sonst nicht anweisen läßt. Heutzutage ist man viel eher geneigt, in diesem *nä ein altes pronominales Element zu sehen..., zu dem die Kasussuffixe traten. Während die Annahme eines Wortes mit der Bedeutung 'Nähe, Seite' sich semantisch sehr begründen läßt, weist die (einsilbige) Form klar auf ein pronominales Element hin. Ein Demonstrativpronomen *nä ist in den verwandten Sprachen gut belegt, ein *nä 'Seite, Nähe' hingegen überhaupt nicht. (Riese 1992: 381.)

Samalle kannalle on asettunut Uralisches etymologisches Wörterbuch, mutta en löydä Rédein ja Mikolan puheena olevia kirjoituksia (Rédei 1973, Mikola 1975, ks. UEW 300-301) sen kirjallisuusluettelosta.

\section{I. n:n sisältävien kaasussuffiksien, adverbien ym. elementtien sanue}

Mikolan esittämä selitys on vakuuttava siinä mielessä, että hänen käsittelemänsä samojedi- ja ugrilaiskielten elementit ovat samaa perua, mutta minun on melko vaikea hyväksyä ajatusta, että niiden lähde olisi 'läheisyyttä' merkitsevä demonstratiivi, se tuntuu nimittäin hyvin keinotekoiselta. Oletettu merkitys näyt- 
tää hyvin uskottavalta, ja merkityksen perusteella kantasanana on voinut olla vain substantiivi.

Nähdäkseni obinugrilaisissa kielissä on muitakin elementtejä (adverbeja, postpositioita, partikkeleita ja kaasussuffikseja), jotka kuulunevat tähän yhteyteen.

\section{I.I. Adverbit}

VOGULI

- $\quad$ KU nōlwa, P LO nāl, So nālwa 'ans Ufer, flußabwärts' (Liimola 1963: 184);

- KU nōlman, P nālam: tä-n., LO nālam '(vom Land und Wald aus gesehen) am Ufer, (vom Ufer aus gesehen) auf dem Fluß, auf dem See', (Munkácsi) LM N nalmén (Liimola 1963: 133-134);

- KU nōlmal, P So nālmal 'auf dem Flußwege, auf der mittleren Fahrstraße' (Liimola 1963: 165);

\section{OSTJAKKI}

- $\quad$ VVj Sur Irt nik, Ni Šer Kaz Syn nŭk, O nik 'Präverb... Zum Fluß hinunter, ans Ufer vom höher gelegenen Land abwärts; auf den Herd, übers Feuer (z. B. den Kessel hängen), zum Herd hin, zur Haustür hin';

- $\quad$ VVj Sur nim, Šer Kaz Syn nĭm, O nim 'Unter-, Ufer-, weiter unten am

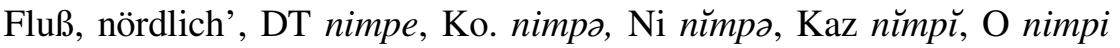
'dem Ufer zu gelegener Rand einer Stadt, eines Dorfes, untere Seite, Vorderseite';

- $\quad$ VVj Sur Irt nämən, Ni Šer Kaz namən, O nämən 'am Ufer, am Rand eines Sumpfes, näher am Ufer, weiter unten, in der (Nähe der) Tür, hinten';

- Sur nämastä, Irt nämətta, Ni namatta, Kaz namasta, Syn namalta, O nämalta 'weiter vom Ufer weg (auf den Fluß, z. B. fahren), vom Ufer aufs Land hinauf, vom Ufer her' (DEWOS 984-986).

Ostjakin sanat viittaavat siihen, että jo muinaisostjakissa olivat käytössä vokaalivaihtelulliset rinnakkaismuodot *nim *näm(-ən, -əltä). Ostjakin murteissa on vielä kaksi tällaista adverbiperhettä: VVj küm, Sur kim ( kem) jne. 'hinaus, Außen-' VVj kə̈mən, Sur kemən jne. 'draußen, im Freien, auf der Straße' (DEWOS 636-637), VVj Sur Irt num jne. 'nach oben, hinauf, das Obere' VVj nəmân, Trj nomân jne. 'oben befindlich, weiter flußaufwärts befindlich, Oberlauf eines Flusses, Süden, südlich' (DEWOS 988-989).

Pidempien (lokatiivisten ja ablatiivisten) adverbimuotojen $m$ on denominaalinen nominijohdin (vrt. Ravila 1937: 42-43; Liimola 1955-1956: 22-23; 
1962: 301; 1963: 134). Kaasussuffiksittomia, pelkkiä m:llisiä nim-, küm- ja num-muotoja käytetään myös adjektiiveina, ei ainoastaan adverbeina.

Näiden adverbien joukkoa voi vielä laajentaa yhdellä adverbiperheellä, joka tunnetaan sekä ostjakissa että vogulissa (joskaan ei kovin yleisesti) ja jonka jäsenet eivät muodosta edellisten kaltaista järjestelmää, mutta kuuluvat epäilemättä tähän:

- OSTJ. J àıəm jne. "Attribut zu 'Seite"” (DEWOS 78) < kantaostj. *älam,

- VOG. TJ älam: ä.-pält jne. 'jenseits...' (Liimola 1962: 299-300; 1963: 189) < kantavog. *ä̈lsm.

Siteeraamieni obinugrilaisten sanojen perusteella näyttää varmalta, että niiden edeltäjillä oli $m$-johtimella muodostetut johdokset sekä attribuutteina että latiivisina ja lokatiivisina adverbeina jo obinugrilaisessa kantakielessä. Ostj. *nim *nämən eroaa muista adverbeista vain siinä, että väljävokaalista vartalon muunnosta käytetään vain adverbiaalisilla kaasussuffikseilla laajennettuna. Tähän voisi olla syynä se, että perussanaksi otaksumani *näm 'hierher, in die Nähe; hier, in der Nähe' on vähitellen kehittynyt postpositioksi ja painollisena partikkelinakin se on voinut liittyä nomineihin, adverbeihin, pronomineihin ja on askel askelelta menettänyt itsenäisen sanan statuksensa.

\section{I.2. Postpositiot, partikkelit, kaasussuffiksit}

Ostj. Trj J -nam/-näm, Sal -nam approksimatiivipääte, esim. Trj pĕsännäm 'pöytään päin; gegen den Tisch', ŏ\%pinam 'ovea kohti; gegen die Tür' (Karjalainen 1964: 229; vrt. pěsän 'Tisch', ŏ \%pi 'Tür'), sopii tähän yhteyteen sekä äänteellisesti että funktionaalisesti. Tämä -nam/-näm oli alkuaan kai painotuksen ilmaiseva partikkeli, joka liittyi etupäässä pronomineihin ja adverbeihin, kuten se nykyäänkin esiintyy itäisimmissä murteissa, esim. Vj mä mĕnnäm 'minä itse', nö̈ nö̈nnäm 'sinä itse', $\mathrm{VVj}$ t'inäm 'tuolla', Vj t'unam 'tuonne', [Terëškin] Trj t'enam 'tuonne' (ks. Honti 1984: 62). ${ }^{2}$ Lisäksi näyttää mahdolli-

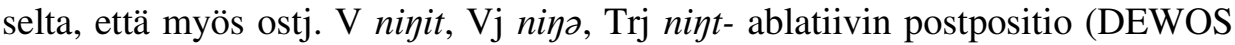
1006) on tämän saman perheen jäsen, mutta sen elementit $\eta(k), t$ jäävät ainakin toistaiseksi vaille selitystä.

\section{Kritiikkiä muiden tutkijoiden esittämistä etymologisista selityksistä}

Olen eri mieltä siitä, että tämä postpositioiden ja päätteiden perhe olisi syntynyt pronominista, kuten Rédei ja Mikola ovat otaksuneet. Syynä tähän on se tosiseikka, että demonstratiiveja käsittelevässä etymologisessa kirjallisuudessa

\footnotetext{
2 Tästä ongelmasta yksityiskohtaisemmin ks. artikkelini Péter Hajdún muistolle omistetussa Nyelvtudományi Közleményekin osassa 100 (Honti 2003).
} 
luetellut, demonstratiiveista selitetyt ei-pronominaaliset ja ei-monikolliset sanat ovat etymologisen pesyeen (hyvin) epävarmoja jäseniä (ks. Rédei 1973: 312313), vrt. "*na 'der hier, dieser da' FU" (UEW 297), "*nä ( *ne ?*ni) 'dieser; ?der, jener' FP, ?U” (UEW 300-301) ja "*no 'jener' FW, ?U” (UEW 306-307) (tästä kysymyksestä ks. vielä Honti 1997: 34-35). Epäilykseni syyt ovat seuraavat:

1. Etymologisten kannanottojen perusteella näyttää todennäköiseltä, että *n-alkuiset pronominit ovat peräisin suomalais-volgalaisesta kantakielestä, mutta ne voivat olla paljon vanhempiakin, ja varmasti ovatkin, sillä possessiiviparadigman monikon tunnus ja objektiivisen verbintaivutuksen monikollisen objektin numerustunnus palautuvat varmasti tähän pronominiin (vrt. Honti 1997: 34). Nähdäkseni uralilaisessa/suomalais-ugrilaisessa kantakielessä demonstratiiveja oli sananalun suhteen kaksi ryhmää:

(a) Toiseen kuuluivat ne, jotka sisälsivät sanan alussa oraalisen konsonantin yksikössä ja nasaalin monikossa, eli numerukset ilmaistiin suppleetiolla (näin olen UEW:n kannanotosta poiketen sitä mieltä, että eroavat sananalkuiset vartalot olivat numeruseron kantajia): $(\alpha)$ johonkin lähelle viittaavat: *tä (UEW 513-515) *nä, *ta (UEW 505) *na (UEW 297), ( $\beta$ ) anaforiset/kataforiset tai kauas viittaavat: *to (UEW 526-528) *no (UEW 306-307), *će (UEW 3334) *ńe (ks. UEW 300-301).

(b) Toisen ryhmän sananalkuinen äänne oli vokaali; tähän kuuluneiden pronominien monikosta minulla ei ole aavistustakaan: $(\alpha)$ lähelle viittaava: $*_{e}$ $(\mathrm{UEW} 67) \sim *$ ?, ( $\beta$ ) kauas viittaava: *o/*u (UEW 332) *?.

Vastaamatta on jäänyt vielä myös kysymys siitä, minkälainen ero oli (a) lähelle ja kauas (kauemmas) viittaavilla palatovelaarisilla pronomineilla ja (b) konsonantti- ja vokaalialkuisilla demonstratiiveilla; piti nimittäin olla jonkinlainen "työnjako".

2. Demonstratiivi, jonka merkitys olisi ollut 'läheisyys; Nähe', per definitionem ei voi eikä voinut olla olemassa.

3. Käsittelemäni postpositiot ja päätteet ovat helpommin selitettävissä Liimolan otaksuman pohjalta (ks. alempana).

\section{I.}

Olen sitä mieltä, että ostj. VVj Sur jne. nämən 'am Ufer usw.' adverbien ja niille sukua olevien vogulin kaasuspäätteiden vartalon muoto obinugrilaisessa kantakielessä on voinut olla *nä-. Kantaostjakin *nim on voinut syntyä *nämmuodosta adverbien *küm *kə̈mən, *num *nəmân analogiasta. Näin alkunsa saaneelle vartalolle *ni- on voinut rakentua ablatiivinen postpositio *niך-. Kaikkien tähän liittämieni elementtien ugrilainen lähtömuoto oli *n-alkuinen etuvokaalinen ja 'Nähe, Raum in der Nähe von etwas; Flußufer' -merkityksinen sana. Jos tämä pitää paikkansa, yhä todennäköisempi on Liimolan Budenzin ja Fokosin hypoteesille perustuva selitys, jonka mukaan postpositiosta syntyneet ugri- 
laiset päätteet palautuvat nominiin *nä- 'Nähe' (Liimola 1963: 64-67, 95, 120123) - jopa riippumatta siitä, voitaisiinko rakentaa (pelkkään mielikuvitukseen kuuluvalle) 'Nähe'-merkityksiselle pronominille perustuvia pilvilinnoja. Mainitsen vielä, että Liimola ei halunnut ottaa kantaa unk. -nak/-nek päätteen ja neki jne. postposition etymologiaan (Liimola 1963: 98), mutta ei ole mitään syytä epäillä, etteivät nekin kuulu tähän sanapesueeseen. Nähdäkseni joen rantaan verrattua liikkumista ja sijaintia havainnollistavien postpositioiden johtaminen nominista *nä- 'Nähe, Raum in der Nähe von etwas, Flußufer' voi tehdä Budenzin esittämän selityksen todennäköisemmäksi. Epäilemättä tällainen yksitavuinen nomini on ristiriidassa kantakielten ajan sanaston äänneasun kanssa, odotuksenmukainen nimittäin olisi kaksitavuinen nomini. Tuntuu kuitenkin luontevalta olettaa - ainakin ugrilaisten kielten perusteella - muodon *nä 'Nähe' sijasta muoto *näjs 'Nähe', joka postpositioksi kehittyessään on välttämättä lyhentynytkin; lyhentymistä on edesauttanut myös sen painottomuus. Aikakauskirjan toimituksen kautta saamani kommentin nojalla olen kiinnittänyt huomiota siihen, että samojedissa esiintyy * $\eta$ :llisiä muotoja, ja niiden perusteella uralilaisen kantakielen muodossakin olisi pitänyt olla $* \eta$, eikä $* j$. Mutta nähdäkseni obinugrilaiset kielet ovat selvästi $* j$ :n kannalla (vrt. Csúcs et al. 1991: 137-138), joka on samojedikielten kannalta epätodennäköinen (vrt. Csúcs et al. 1991: 138); vogulin ja ostjakin kantamuotoon sen sijaan ei oikein sopisi $* \eta$ (vrt. Csúcs et al. 1991: 152-153, samojedin osalta mts. 153-154). Ugrilaiset ja samojedilaiset sanueet kuuluvat etymologisesti varmasti yhteen, näin voin vain olettaa vaihtoehtoiset kantamuodot: $\mathrm{U} * n \ddot{\eta} \eta з$ tai *näj3, joiden sanansisäiset konsonantit $(\eta$ ja $j$ ) ovat yleensä taipuvaisia katoamaan; katoamisen jälkeen joko kantasamojedissa oli lisätty $* \eta$ vartaloon, tai kantaugrissa $* j$. Tämän muotoon *näjz palautuvan ugrilaisen postposition suorat jatkajat ovat pohjoisostjakin ja vogulin latiivinpääte sekä unk. murt. latiivinpääte -ni, -nyi. Riese kirjoittaa ugrilaisten päätteiden lähteenä olevan postposition yhteydessä: "Früher hat man die lativische Postposition in der Form $*_{n} \ddot{a}-k>*_{n} \ddot{a}-\gamma$ rekonstruiert. Aufgrund der lautlichen Entsprechungen halte ich jedoch *nä-j für wahrscheinlicher" (Riese 1992: 381). Tämä on vihdoin sopusoinnussa itse rekonstruoimani muodon kanssa.

\section{2.}

Liimola on vertaillut vogulin postpositiota KU ńūpal', P nūpəl', LO nūpal 'gegen, auf, zu' unkarin adessiivisuffiksiin -nál/-nél ja postuloinut niiden lähteeksi myös 'läheisyyttä (Nähe)' merkitsevän substantiivin (Liimola 1963: 71-73). Tärkeimmät unkarin kielen etymologiset sanakirjat ovatkin hyväksyneet tämän

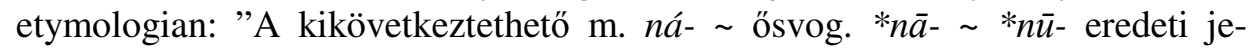
lentése 'közelség; Nähe' lehetett, de ez nem igazolható. [Uusi jakso] Az ugor alapalak: *na-" (MSzFE 3: 462; samaan tapaan TESz 2: 996; EWUng 2: 1014). Sen sijaan sanakirjat UEW (297) ja SSA (2: 199) selittävät nämä ugrilaiset ele- 
mentit demonstratiivista FU *na 'der hier, dieser da'. Kysymys on vain siitä, kumpi vaihtoehto on todennäköisempi.

Jos lähdetään substantiivista 'Nähe', on edessämme tavanomainen kieliopillistumisprosessi: "possessiivirakenne > postposition sisältävä rakenne > kaasuspäätteellä varustettu substantiivi". Varjopuolena on epäilemättä se seikka, että kielikunnassamme ei ole osoitettavissa muita *nøj(3) 'Nähe' substantiiviin palautettavia sanoja, apusanoja tai suffikseja; tilanne on muuten sama kuin jaksossa 2 esitettyjen suffiksien jne. tapauksessa, nim. vog. T -nä $t$ jne. komitatiivipäätteiden osaltakaan emme löydä *nöj(3) 'Nähe' sanan suoria jatkajia uralilaisista kielistä.

Jos haluamme selittää vogulin postposition LO nūpal 'gegen, auf, zu' jne. demonstratiivin FU *na'der hier, dieser da' jatkajaksi, suurin vaikeus ilmenee siinä, että kielissä, jotka ovat säilyttäneet tämän demonstratiivin pronominina, sillä on selvästi monikollinen funktio; sama on asianlaita muidenkin $n$ :llisten demonstratiivien tapauksessa, vrt. esim. sm. tämä nämä, tио nио, se ne (ks. esim. Majtinskaja 1964: 29-30). Vaikka ilmiö esiintyykin hyvin pienessä nominiryhmässä, so. demonstratiiveissa, tämänkaltainen suppletiivinen numerusmuodostus on agglutinoivissa kielissä epätavallista (nykyään se on olemassa enää suomalais-permiläisissä kielissä). Tämä piirre on nähdäkseni peräisin uralilaisesta kantakielestä, eikä ole ihme, että se on kadonnut samojedi- ja ugrilaiskielistä ja läntisessäkin kieliryhmässä se on taantumassa, vrt. viron too 'jener' nood 'jene (Pl.)' $\leftrightarrow$ sm. tuo 'jener' nиo 'jene (Pl.)', md. t'e 'dieser' ńe 'diese (Pl.)' $\leftrightarrow t^{\prime} e$ 'dieser' $\sim$ ńet' ${ }^{\prime}$ diese (Pl.)' $\leftrightarrow s^{\prime} e$ 'jener' $\sim$ śet' 'jene (Pl.)', tšer. $t i$ 'dieser' ninə 'diese (Pl.)' $\leftrightarrow t i$ 'dieser' ninawlä 'diese (Pl.)', tudo 'jener' tudowlak 'jene (Pl.)', syrj. si je 'er' naje 'sie (Pl.)' ↔ si je 'jener' si jejas 'jene (Pl.)'; tasoittuminen onkin jo päättynyt votjakissa: so 'er, jener' $\sim$ soos 'sie, jene (Pl.)', ta 'dieser' taos 'diese (Pl.)' (vrt. Majtinskaja 1964: 30, 77; 1969: 95-96, 99-100). Selkupissa $n$-alkuinen demonstratiivi voi olla muinaisen dualismin perifeerinen todistaja ja käytöstä syrjäytyneen monikon edustaja.

\section{Lopuksi}

Yhteenvetona voin todeta, että jos vertaamme Liimolan esittämää selitystä yllä käsiteltyjen ugrilaisten postpositioiden ja kaasussuffiksien alkuperästä muiden esittämiin ehdotuksiin, Liimolan ajatuskulku näyttää paljon todennäköisemmältä, jopa täysin vakuuttavalta. Hänen esittämiensä todisteiden ainoana heikkona puolena on se seikka, että uralilaisissa kielissä ei ole osoitettavissa nominien *nöj(3) 'Nähe' ja *nøj(3) 'Nähe' välittömiä jatkajia substantiiveina. Tämä ei kuitenkaan voi yllättää historiallis-vertailevaa kielitiedettä vähänkin tuntevaa tutkijaa, onhan päivänselvää, että kaikki vanhemman kielimuodon sanat eivät voi säilyä ikuisuuteen, jopa niiden valtaosa katoaa ajan myötä hyvin erilaisista syistä. 


\section{Kirjallisuus}

Budenz, József 1884-1894: Az ugor nyelvek összehasonlító alaktana. Budapest: Magyar Tudományos Akadémia.

Csúcs, Sándor \& Honti, László \& Salánki, Zsuzsa \& Varga, Judit 1991: Statistik der uralischen Lautentsprechungen. Linguistica, Series B, Documenta, 1. Budapest: MTA Nyelvtudományi Intézete.

DEWOS = Steinitz, Wolfgang 1966-1993: Dialektologisches und etymologisches Wörterbuch der ostjakischen Sprache. Berlin: Akademie Verlag.

EWUng 2 = Benkő, Loránd (toim.) 1995: Etymologisches Wörterbuch des Ungarischen. Band II. Kor-Zs. Budapest: Akadémiai Kiadó.

Fokos, Dávid 1910: A -nott, -nól, -ni ragok eredetéről. - Magyar Nyelvőr 39: 158-162, 226-228.

Honti, László 1975: System der paradigmatischen Suffixmorpheme des wogulischen Dialektes an der Tawda. Janua Linguarum. Series Practica 246. Budapest - Den Haag - Paris: Akadémiai Kiadó - Mouton.

Honti, László 1984: Chrestomathia ostiacica. Budapest: Tankönyvkiadó.

Honti, László 1997: Numerusprobleme (Ein Erkundungszug durch den Dschungel der uralischen Numeri). - Finnisch-Ugrische Forschungen 54: 1-126.

Honti, László 2003: Az osztják approximativusrag eredete (avagy egy uráli szócsalád nyomában). - Nyelvtudományi Közlemények 100: 168-176.

Itkonen, Terho 1992: Ugrilaisten kielten karitiivista. - Pál Deréky, Timothy Riese, Marianne Sz. Bakró-Nagy \& Péter Hajdú (toim.), Festschrift für Károly Rédei zum 60. Geburtstag - Emlékkönyv Rédei Károly 60. születésnapjára. Wien - Budapest. 221-237.

Janhunen, Juha 1977: Samojedischer Wortschatz. Gemeinsamojedische Etymologien. Castrenianumin toimitteita 17. Helsinki.

Karjalainen, K. F. 1964: Grammatikalische Aufzeichnungen aus ostjakischen Mundarten. Bearbeitet und herausgegeben von E. Vértes. Suomalais-Ugrilaisen Seuran Toimituksia 128. Helsinki: Suomalais-Ugrilainen Seura.

Liimola, Matti 1955-1956: Zur wogulischen Formenlehre. - Suomalais-Ugrilaisen Seuran Aikakauskirja 58: 3: 1-65.

Liimola, Matti 1962: Etymologisches aus den ugrischen Sprachen. - Commentationes Fenno-Ugricae in honorem Paavo Ravila. Suomalais-Ugrilaisen Seuran Toimituksia 125. Helsinki: Suomalais-Ugrilainen Seura. 289-316.

Liimola, Matti 1963: Zur historischen Formenlehre des Wogulischen. I. Flexion der Nomina. Suomalais-Ugrilaisen Seuran Toimituksia 127. Helsinki: SuomalaisUgrilainen Seura.

Majtinskaja = Майтинская, К. Е. 1964: Местоимения в мордовских и марийских языках. Москва: Наука.

Majtinskaja = Майтинская, К. Е. 1969: Местоимения в языках разных систем. Москва: Наука.

Mikola, Tibor 1975: Die alten Postpositionen des Nenzischen. Budapest - Den Haag: Akadémiai Kiadó - Mouton \& Co. 
MSzFE 3 = Lakó, György (toim.) 1978: A magyar szókészlet finnugor elemei. Etimológiai szótár. III. kötet. N-ZS. Budapest: Akadémiai Kiadó.

Nevis, Joel Ashmore 1988: A morphotactic paradox in Northern Saame: comitative -guim. - Ural-Altaische Jahrbücher. Neue Folge 8: 38-50.

Ravila, Paavo 1937: Über das finnisch-ugrische Komparativsuffix. - Finnisch-Ugrische Forschungen 24: 29-58.

Rédei, Károly 1973: Über die Demonstrativpronomina in den uralischen Sprachen. Commentationes Fenno-Ugricae in honorem Erkki Itkonen sexagenarii die XXVI mensis aprilis anno MCMLXXIII. Suomalais-Ugrilaisen Seuran Toimituksia 150. Helsinki: Suomalais-Ugrilainen Seura. 311-319.

Riese, Timothy 1992: Zur Entwicklung des Kasussystems im Wogulischen. - Pál Deréky, Timothy Riese, Marianne Sz. Bakró-Nagy \& Péter Hajdú (toim.), Festschrift für Károly Rédei zum 60. Geburtstag - Emlékkönyv Rédei Károly 60. születésnapjára. Wien - Budapest. 379-388.

SSA 2 = Itkonen, Erkki \& Ulla-Maija Kulonen (toim.) 1995: Suomen sanojen alkuperä. Etymologinen sanakirja. 2. L-P. Helsinki: Suomalaisen Kirjallisuuden Seura - Kotimaisten kielten tutkimuskeskus.

TESz 2 = Benkő, Loránd (toim.) 1970: A magyar nyelv történeti-etimológiai szótára. Második kötet. H-Ó. Budapest: Akadémiai Kiadó.

UEW = Rédei, Károly (toim.) 1988: Uralisches etymologisches Wörterbuch. Band I. Uralische und finnisch-ugrische Schicht. Budapest - Wiesbaden: Akadémiai Kiadó - Otto Harrassowitz.

\section{László Honti}

Università degli Studi di Udine

Dipartimento di Glottologia e Filologia Classica

Via Mazzini 3

IT-33100 Udine 